\title{
How Concentrated are Police on Crime? A Spatiotemporal Analysis of the Concentration of Police Presence and Crime
}

\author{
Philipp M. Dau ${ }^{1}$, Christophe Vandeviver ${ }^{1,2}$, Maite Dewinter ${ }^{3}$, Frank Witlox ${ }^{3,4,5}$, Tom Vander \\ Beken $^{1}$ \\ ${ }^{1}$ Department of Criminology, Criminal Law and Social Law, Ghent University, Universiteitstraat 4, \\ Ghent 9000, Belgium \\ ${ }^{2}$ Research Foundation-Flanders (FWO), Egmontstraat 5, Brussels 1000, Belgium \\ ${ }^{3}$ Department of Geography, Ghent University, Krijgslaan 281 S8, Ghent 9000, Belgium \\ ${ }^{4}$ Department of Geography, University of Tartu, Vanemuise 46, Tartu 51014, Estonia \\ ${ }^{5}$ College of Civil Aviation, Nanjing University of Aeronautics and Astronautics, Nanjing 210016, \\ China
}

Direct correspondence to: Christophe Vandeviver, Department of Criminology, Criminal Law and

Social Law, Ghent University, Universiteitstraat 4, 9000 Ghent, Belgium.

Email: Christophe.Vandeviver@UGent.be

Funding This work was supported in part by the Ghent University Research Council (UGent-BOF) Interdisciplinary Research Project funding scheme [BOF18/IOP/001 to C.V., T.V.B., F.W.]. Christophe Vandeviver's contribution was supported in part by the Research Foundation Flanders (FWO) Postdoctoral Fellowship funding scheme [12CO619N to C.V.]. Frank Witlox's contribution was supported by the Estonian Research Council [PUT PRG306 501 to F.W.].

Conflicts of interest The authors declare no conflict of interests.

Acknowledgements The computational resources (Stevin Supercomputer Infrastructure) and services used in this work were provided by the VSC (Flemish Supercomputer Centre), funded by Ghent University, FWO and the Flemish Government - department EWI.

We would like to thank the Antwerp Police Department (APD) for providing us with the anonymized datasets.

Availability of data and materials The research data (consisting of police recorded crime data and patrol car GPS data) and code cannot be publicly shared.

\section{QUICK MENU:}

\section{INTRODUCTION}

DATA

METHODS

RESULTS

DISCUSSION

CONCLUSIONS 


\section{How Concentrated are Police on Crime? A Spatiotemporal Analysis of Concentration of Police Presence and Crime}

Purpose Police patrol has undergone an evidence-based and data driven transition in the beginning of the $21^{\text {st }}$ century. While crime patterns are well researched, patterns of police presence are not. Despite the abundance of available GPS data, little is known about the spatiotemporal patterns of police forces. Given the paucity of evidence on where everyday policing takes place, we ask: what spatiotemporal patterns of police exist, how do these patterns change over time, and how do these correspond to local crime patterns?

Methods Therefore, we analysed more than 77 million GPS signals from 130 police patrol cars and more than 50,000 recorded crimes from 2019.to investigate where and when police patrols are present. All data were geocoded and map matched using high performance computing.

Results We found that police, much like crime, concentrates on a small proportion of street segments and that the spatial concentration experiences temporal instability at the micro level. Further, spatiotemporal police presence and its concentration appear to be unrelated to local levels of crime and crime concentration.

Conclusions These findings inform police chiefs and researchers alike and enable alterations of patrol deployment in order to refine the spatiotemporal focus of police on local crime. Future considerations are required to research optimal spatiotemporal alignment of police presence to effectively prevent crime.

Keywords: tracking, policing, GPS, police presence, hot spots

\section{Introduction}

"If crime is so concentrated at specific places in the city, then policing and other crime prevention resources also should be concentrated" (Weisburd, 2015) 
Policing has always been at the core of police officer's duties (see, Carrabine, 2009; Emsley, 1983, 2006; Kelling et al., 1974; Wain \& Ariel, 2014). Over the centuries policing practices have evidently changed. What started with foot patrol based "fixed-point systems"1 rapidly developed into motor patrol, where officers were assigned to patrol the same beats continuously. This change from a reporting intensive and strictly guided approach to large police beat oriented strategies provided officers with a novel level of discretion and freedom (Wain \& Ariel, 2014). Being able to independently decide where, when, and how to police while on duty still remains highly important to police officers (Cordner, 1981; Koper et al., 2020). Prior research has shown that crime exhibits a high spatiotemporal concentration (Weisburd 2015) and that focused police action can effectively reduce reported crime (see, Ariel et al., 2019; Braga, Turchan et al., 2019; Braga, Weisburd, \& Turchan, 2019; Hutt, 2020). While research on crime has benefitted from evidence-based analyses (e.g., Lum \& Koper, 2017; Mitchell, 2017; Sherman, 2006, 2013; Telep, 2013) and a focus on microgeographic units (e.g., Andresen et al., 2020; Ariel et al., 2019; Hutt, 2020; Li et al., 2011; Vandeviver \& Steenbeek, 2019; Weisburd et al., 2010; Weisburd, 2015), everyday policing has received comparingly little attention. A recent survey in the U.S. has shown that less than one third of police agencies employ hot spots units and just about half are engaged in crime analysis (Koper et al., 2020). In general, very little is known on how evidence-based research on crime and police is translated into the everyday practice of policing. This urges research to identify patterns of police presence to improve patrol allocation in correspondence to local crime.

\footnotetext{
1 "Fixed" reporting points were distributed across patrol beats for officers to report back to patrol sergeants and to receive intel on their assigned patrol beat. This system offered additional security for officers but came with a certain level of supervision (Wain and Ariel 2014).
} 


\section{Concentration of Crime}

Evidence-based research has shed light on the distribution of crime as well as on policing effectiveness and has proven central assumptions of theories in Environmental Criminology (Lum \& Koper, 2017; Mitchell, 2017; Weisburd, 2015). Routine activity theory and crime pattern theory hypothesize that crime clusters in specific places (see, Brantingham \& Brantingham, 1993; Cohen \& Felson, 1979; Felson, 2008). The main rationale behind these theories is that, by the accumulation of criminal opportunities in certain places, the overall crime risk at these locations is elevated (Felson \& Clarke, 1998; Nagin et al., 2015), as the rational decision matrix of offenders gets tilted toward committing criminal acts (Cornish \& Clarke, 1986). This has been confirmed through various crime studies that used microgeographic units (e.g., street segments) for analysis (e.g., Andresen et al., 2017; Ariel et al., 2016; Ariel et al., 2019; Braga, Turchan et al., 2019; Levin et al., 2017). Crime clusters unevenly across place and time and is not random. Weisburd (2015) has shown that across eight cities half of all crime incidents concentrate on $2.1 \%$ to $6.0 \%$ and a quarter of all crime on $0.4 \%$ to $1.6 \%$ of street segments. Andresen et al. (2017) provided evidence that spatial crime concentration exhibits a temporal stability over a ten year period. Due to temporally stable concentrations and the fact that there are often more spatial units than crimes, a proportion of street segments naturally tends to remain "crime-free" (Bernasco \& Steenbeek, 2017; Levin et al., 2017). Unfortunately, temporal research on crime and policing at the micro level (e.g., street segments, street blocks) and especially so in combination with spatial analysis, has not received much attention (Felson \& Poulsen, 2003; Ratcliffe, 2010).

Nevertheless, contemporary findings have been well-translated into police research through the introduction of focused police actions, most importantly hot spots policing (e.g., Ariel et al., 2019; Braga, Turchan et al., 2019; Braga, Weisburd, \& Turchan, 2019; Mitchell, 2017; Williams \& Coupe, 2017). When policing is focused upon crime hot spots, crime can be 
reduced effectively. With what is regarded as the Koper curve, Koper (1995) indicated that police officers have to be present at crime hot spots for 10 to 15 minutes to effectively realize these crime reduction effects. Williams \& Coupe (2017) have further provided evidence that police visits to hot spots of crime are more effective when delivered longer rather than more frequent, given that the visits stay within the temporal extents of the Koper curve. However, these findings remain contested. For example, Mitchell (2017) arguing that more frequent visits deter more crime than longer ones do. To date, only few studies addressed compliance issues and controlled for actual deployed police presence, in length or frequency (Ariel et al., 2016; Collazos et al., 2020; Schaefer et al., 2019; Williams \& Coupe, 2017). For example, Ariel et al. (2016) reported compliance rates of $53 \%$ for 15 -minute patrols, while Williams \& Coupe (2017) reported compliance rates of about $67 \%{ }^{2}$.

\section{Policing Activity Research}

Policing has attracted widespread interdisciplinary interest outside of Criminology and was subject to various ex-ante research (e.g., Adler et al., 2014; Chen et al., 2015; Dewinter et al., 2020; Sacks, 2000). Research on policing has mostly been limited to considerations of staffing demands, fast response, and measures of uncommitted officer time (see, Cordner, 1979; DeAngelo et al., 2020; Famega, 2005; Kenneth R. Chelst, 1981; McCabe, 2013). A study by Davies and Bowers (2019) analysed general supply and demand patterns of policing and emergency calls. To our knowledge, no research has yet focused on the spatiotemporal analysis of police presence and crime.

\footnotetext{
${ }^{2}$ Compliance rates in percent refer to the discrepancy between planned and deployed police presence. This means that when officers are to conduct 15-minute patrol, at times they are present at patrol locations for about 10 minutes or less.
} 
This is mainly due to two structural challenges. First, police chiefs are faced with balancing surveillance and accountability of police officers (Wain \& Ariel, 2014). Police officers value discretion and providing them with freedom on where and how to patrol are important aspects of job satisfaction (Cordner, 1981; Koper et al., 2020; Wain \& Ariel, 2014). In contrast, introducing performance evaluations can potentially be perceived as loss of trust in officer's intuition and patrol conduct. Second, highly detailed spatiotemporal analyses have just recently been enabled through technological advances in the Global Positioning System (GPS) (Davies \& Bowers, 2019; Elevelt et al., 2019; Ridgeway, 2018; Vandeviver \& Bernasco, 2017). Documenting patrol activity has so far been tedious and cost-intensive work. Either, police officers used paper-based documentation to report how, when, and where they were engaging in policing tasks (Elevelt et al., 2019) or radio-calls were manually documented by police staff at headquarters (Ariel et al., 2019). With the introduction of easily accessible as well as lowcost AVLs (Automated Vehicle Locator) and handheld GPS trackers, police departments are now able to track their officers and vehicles while being deployed (Davies \& Bowers, 2019; Ridgeway, 2018; Wain \& Ariel, 2014). Although this technological improvement allows for more detailed and precise data collection, researchers are now facing substantial amounts of data to analyse. Due to very precise GPS pings ${ }^{3}$, research is often limited to look at few hotspots or short periods of time (Davies \& Bowers, 2019; Oatley et al., 2019). For example, Oatley et al. (2019) studied bike patrol officer's ability to map crime hotspots over a ten-week period, which required analysis of 1.7 million GPS signals ${ }^{4}$ from smartphone devices.

As Weisburd (2015) suggested, we expect police presence to be just as concentrated as crime. Therefore, this paper aims to answer how much police is concentrated in space and time

\footnotetext{
${ }^{3}$ GPS pings describe the frequency with which GPS signals are send to the receiving unit. Pings vary due to technology and patrol types. Foot patrols are tracked through body worn radios and send signals every 30 seconds to five minutes. Motor patrol can carry more powerful AVLs, which often have GPS pings of under ten seconds (Hutt et al. 2018).

${ }^{4}$ Oatley et al. (2019) have not reported the GPS ping of the tracking app used to collect the officer GPS data.
} 
and how well this concentration corresponds to local crime patterns. We will first describe the datasets and case study before we will move to the empirical results, showing that policing activity is highly concentrated on a small proportion of street segments and remains rather stable across space but not time. Further, the concentration of police corresponds weakly with local crime. We argue, that these novel findings contribute to the understanding of how policing is carried out in everyday practice and encourage comparative research on the concentration of police presence.

\section{Data}

We use data provided by the Antwerp Police Department (APD). The APD is policing the City of Antwerp across 21 police zones. Antwerp, as the second-largest city in Belgium, stretches over $204 \mathrm{~km}^{2}$ and is populated by around 530,000 people. Data were collected from January $1^{\text {st }} 2019$ to December $31^{\text {st }} 2019$ from the APD crime database and through AVLs from 130 patrol cars ${ }^{5}$ with a general GPS ping of four seconds. In order to understand the spatiotemporal concentration of policing activity, we analysed 77,680,983 unique GPS signals from patrol cars and 52,512 reported crime events. The crime data were categorized according to APD classification and aggregated to internationally comparable categories. All crimes that categorized as public order infractions were dropped from the dataset. For more detailed analysis, seven crime types were selected: drug crimes, theft, motor vehicle theft, burglary, assault, vandalism, and criminal homicide. Open-source street network data was retrieved through the Flemish Roads Register and encompassed 31,156 segments. All data were processed using Python 3.8 and R 3.6. The geocoordinates were map matched with a static map matching algorithm, which was run on a high-performance computing cluster.

\footnotetext{
${ }^{5}$ The 130 analysed patrol cars constitute $38 \%$ of the APD vehicle fleet, including unmarked and service cars.
} 


\section{Methods}

A multi-level spatiotemporal analysis has been deployed. Descriptive statistics are used to present the concentration of police presence and crime on the meso and micro level. Police presence is calculated from the GPS data of patrol cars. Signals are assigned a time value (e.g., four seconds) based on the calculated lag between two consecutive pairs of GPS pings. We excluded all GPS signals that were recorded at the police headquarter or at police stations. Crime levels correspond to the number of reported crimes. Concentration is operationalized as the proportion of spatial units that receives a certain percentage of police presence in minutes and hours or a certain percentage of crime events and as the Gini coefficient. It is important to note, that a low proportion expresses a high concentration and vice vers $a^{6}$. This measurement was adapted from Weisburd (2015).

Spatially, the meso level consists of the APD police zones $\left(\mathrm{n}=21\right.$, mean area $\left.=9.58 \mathrm{~km}^{2}\right)$ and the micro level of all street segments in $\operatorname{Antwerp}^{7}(n=31,147$, mean length $=93.3 \mathrm{~m})$, respectively. Both levels were included, as the zones are of high importance for the police department in terms of patrol management and street segments allow for a fine-grained spatial analysis of crime and police. This was done to investigate how much we can learn from the two distinct levels of analysis in regard to the spatiotemporal patterns of police presence and crime.

Temporally, policing activity and crime events were analysed at the month, week, day, and hour level. In addition, linear correlation analyses (Pearson's correlation coefficient) were used to investigate the association between the level of police and crime and their respective

\footnotetext{
${ }^{6}$ Given that $10 \%$ of all streets cause $25 \%$ of all crime at time $\mathrm{x}$ and that $5 \%$ of all streets cause $25 \%$ of all crime at time $y$, it follows that $5 \%$ is more concentrated as a lower number of streets causes $25 \%$ of crime.

${ }^{7}$ Open access data retrieved from Flemish Roads Register (https://www.vlaanderen.be/)
} 
concentration at the 25,50 , and $75 \%$ level $^{8}$ of street segments. We also employed a week-rank comparison between the street segments that received most police presence and crime events, respectively. The rank comparison was conducted on, both, the one hundred and ten most frequented street segments.

\section{Results}

\section{Level of Police and Crime}

The number of daily recorded crimes peak at the first day of the year $(n=281)$. Overall the daily number of crimes remains stable over the course of the year ( $\mathrm{SD}=23.1$ ), although slightly rising in the second half of the year. A rise during the summer months (June to August), especially in July $(\mathrm{n}=217)$, and a drop in late December are visible (Figure 1a). In contrast, police presence per day varies substantially over the course of the year, with a decrease as the year progresses $(\mathrm{SD}=118.1)$. The beginning of the year receives little police presence compared to the rest of January (675h). During summer (June to August), police presence remains mostly under the annual median of 769 hours. Likewise, to the trajectory of recorded crimes, police presence experiences a drop in late December (558h) (Figure 1b).

\section{[INSERT FIGURE 1]}

\section{Spatial Concentration of Police and Crime}

Across the police zones, crime is more concentrated than police presence (Figure 2a). The meso level concentration of crime and police presence low differences in magnitude ${ }^{9}$. On the micro level the concentrations are reversed. On the $25 \%$ and $50 \%$ level police presence is more concentrated than reported crime, both across all street segments and non-zero street

\footnotetext{
${ }^{8}$ The $\%$ levels describe that, for example, $10 \%$ of street segments receive $25 \%$ of all recorded crime. The levels for police and crime are fixed, as we are interested in the proportion of street segments that receive these levels of police and crime and, thus, examining their concentration.

${ }^{9}$ As there are 21 zones, each zone presents $4.76 \%$ of all meso level places.
} 
segments ${ }^{10}$. The magnitude of difference varies most across non-zero street segments. Police presence is substantially more concentrated $(25: 0.3 \%, 50: 2.3 \%, 75: 9.1 \%)$ than reported crime (25: $2.0 \%, 50: 9.8 \%, 75: 28.4 \%)$ for non-zero segments. However, at the $75 \%$ concentration level, crime is more concentrated across all street segments (Figure 2b).

\section{[INSERT FIGURE 2]}

Overall, the number of non-zero segments is considerably higher for police presence. Around $81.4 \%(\mathrm{n}=25,373)$ of all street segments receive at least one GPS signal of police presence, while $20 \%(n=6,296)$ do so for crime. The maximum proportions of police presence $(1.5 \%)$ and crime (1.2\%) are roughly similar (see Table 1 in Appendix). Looking at the concentration across all segments, crime (c) experiences a higher level of inequality than police presence (p) (Figure 3). The Gini coefficients for crime and police are 0.92 and 0.89 , respectively.

\section{[INSERT FIGURE 3]}

Across time, the spatial concentrations on the meso level of both, police presence and crime, remain stable. At some months the spatial concentrations are similar but the trend of higher crime concentration is at no point reversed (see Figure 4 in Appendix). Given that the monthly spatial concentration is stable, we were interested in whether the level of police concentration is caused by the same police zones each month. A rank approach showed that the proportion distribution across police zones remained stable over the course of months (see Table 2 in Appendix). Only three police zones experienced rank changes, expressed by the standard deviation of monthly ranks, higher than 2.5 . That means that the same police zones are consistently ranked high and low. As the meso level yields no further insights into microlevel changes within the respective zones, we drop the meso level from here on.

\footnotetext{
${ }^{10}$ Non-zero street segments include all segments that received crime or police presence at least once during the study period.
} 
At the street segment level, the spatial concentration experiences changes in its spatiotemporal trajectory. At the $25 \%$ and $50 \%$ level, the concentrations of police and crime cross each other. Spatial concentration of police at the $25 \%$ level is higher than crime concentration during January to June and shows similar levels thereafter (see Figure 5a in Appendix). At the 50\% level this change already manifests in March. However, for the rest of the year police presence remains less concentrated than crime. For non-zero segments, crime is more concentrated than police presence at each month. Apparently, the trajectories diverge considerably at the $50 \%$ and $75 \%$ level during the period of September to November (see Figure 5b in Appendix). Over the course of the year, we see that police presence is increasingly less concentrated as the year goes on and that crime concentration remains rather stable over time.

Over the course of the day, the spatial concentration of police and crime shows instability and dissimilarities. Across all street segments, police presence is less concentrated than crime at each hour of the day at the $50 \%$ and $75 \%$ level, except for the time between 6.00 a.m. and 6.59 a.m. At the $25 \%$ level, police presence is mostly more or equally concentrated than crime (see Figure 6a in Appendix). At non-zero street segments, spatial concentration is more instable. During night and early morning (1 a.m. to 7 a.m.) crime is more concentrated than police presence but remains less concentrated thereafter. A similar but weaker trend is visible at the $50 \%$ level of concentration. At the $25 \%$ level, police presence is consistently more concentrated than crime (see Figure 6b in Appendix). Overall, police presence experiences less variation in its concentration over the course of the day than crime. 


\section{Temporal Concentration of Police and Crime}

The temporal concentration of police presence and reported crime refers to the proportionate distribution of both resources over time at the micro level. Police presence increases steadily during the days of the week, with the lowest proportion being deployed on Monday and peaking at Saturday, before decreasing again (Figure 7). Crimes are proportionally fewest on Wednesdays but likewise peak during Saturdays. Thus, weekdays receive less crime and police presence than expected under the assumption of an equal temporal distribution. The trajectories of crime and police presence are rather similar in that regard. Likewise, these trajectories progress similarly over the hours of the day (Figure 8). The proportions for both are lowest during morning hours ( 1 a.m. to 7 a.m.) and increase thereafter above expected equal proportions. However, crime and police presence do not peak at the same times during the day. Police is most deployed during the period from 9 a.m. to 2 p.m. The highest proportions of crime are reported at 12 p.m. and at 5 p.m. While crime is at its highest proportion, police presence steadily reduces and regresses to the level of equal proportions. Although, crime and police follow similar trajectories they are misaligned by about three hours.

\section{[INSERT FIGURE 7]}

\section{[INSERT FIGURE 8]}

\section{Geography of Police and Crime}

The prior analysis has shown that police presence is more concentrated across street segment than crime, especially at the highest level of concentration. However, police presence spreads out across the street network more extensively than crime, which is evident in the higher number of non-zero segments. Spatially this concentration is substantially clustered within the central part of the city (Figure 9). Crime events are more clustered around the centre 
and sparse around the edges of the city's core. Police presence is less clustered and is recorded from South-Eastern parts to the West of the municipality. Highest levels of concentration are along longer segments, which appear as connecting streets within the network. Whereas crime is highly concentrated on visually shorter segments. Further, it appears that street segments with the highest concentration of crime do not receive the highest level of police presence and vice versa. Through the geographic extent of police presence, it also becomes apparent that police presence is spread out further across the street network. Thus, the North-Western part shows many street segments, which receive low levels of police presence, compared to no crime for the same street segments.

\section{[INSERT FIGURE 9]}

\section{Spatiotemporal Independence of Police and Crime}

In order to understand the spatiotemporal relationship of police and crime, we have analysed the daily levels and concentration of police presence and recorded crime. We see that high numbers of crime events lead to a statistically significant lower concentration of crime across street segments. Although the relationship is strong only at the 50\% $(\mathrm{r}=0.610)$ and $75 \%$ $(r=0.856)$ level. The level of crime has almost no statistical influence on the level of police nor on police concentration. The daily levels of crime are temporally stable as there is no relationship between day of year and level of crime $(r=0.007)$. A statistically significant positive correlation is found between all levels of crime concentration (see Table 3). The level of police and concentration of police show statistically significant moderate negative relationships on all levels, apart from a weak negative relationship at the $75 \%$ level $(r=-0.475)$. Thus, the more police are deployed, the more concentrated police presence is in space ${ }^{11}$. The

\footnotetext{
${ }^{11}$ Higher levels of police are negatively associated with the proportion of segments that hold a certain percentage of police presence, thus expressing a higher concentration.
} 
strongest effect from elevated police levels is seen at the $25 \%$ level $(r=-0.598)$. Like crime concentration, strong relationships are found between all levels of police presence concentration. However, levels of police and its concentration are not stable over time. The daily levels of police decline significantly during the course of the year $(r=-0.367)$. Thus, also the police presence concentration declines gradually, most strongly at the $25 \%$ level $(r=0.577)$.

The correlation analysis suggests that crime at the segment level has no statistical relationship with the level of police nor with its concentration. Comparing the distribution of highest weekly ranked street segments for police presence and crime confirms this. We calculated, both, the 100 and ten highest ranked street segments for each week for police presence, all crime, and selected crime types (assault, theft, motor vehicle theft, vandalism, burglary, drug crimes, and criminal homicide). We report four major findings from the weekrank analysis.

First, we see a high level of concentration of police presence and crime, for both modes of analysis. It is important to note that this concentration does not describe the concentration of all crimes or police presence across all segments, but the concentration within the highest ranked street segments. Further, we report a slightly higher concentration at the $25 \%$ level for police presence $(2.38 \%)$ than for crime $(2.64 \%)$ for the 100 highest $(h 100)$ ranked segments, but find that crime $(1.75 \%)$ is substantially more concentrated than police presence $(3.26 \%)$ for the ten highest $(h 10)$ ranked segments (Table 4). Second, the overlap ${ }^{12}$ of street segments that are within both ranked sets is rather low. The overlap between all crime and police presence lies at about $23 \%$ for $h 100$ and $2 \%$ for $h 10$. This supports the dissimilar spatial pattern that is visible in the geographic maps (Figure 9). Third, certain crime types show particularly higher

\footnotetext{
${ }^{12}$ The overlap describes the number of segments that were included in the subsets for the whole year. It shows whether one street segment that ranked at least once in $h 100$ or $h 10$ for police presence is within the set of ranked segments for crime (and crime types). The spatiotemporal exact overlap expresses that one segments ranked the same during the same week for both police presence and crime.
} 
overlap with police presence. At $h 100$ the overlap for assault is at $29.74 \%$, the highest reported overlap across all crime types. At $h 10$ motor vehicle (5.43\%), drug crimes $(4.35 \%)$, theft (4.35\%), assault $(3.26 \%)$, and vandalism $(3.26 \%)$ show higher overlap than all crimes combined. Further, we report high concentrations of crime at both $h 100$ and $h 10$, with theft and drug crimes being most concentrated at the $25 \%$ level (Table 4). Fourth, the spatiotemporal alignment of police presence and crime is found to be low. We calculated the exact overlap of all rankings of police presence, all crime, and all analysed crime types. The spatiotemporal exact overlap did not exceed $0.3 \%$ for any of the crime types nor all crime.

[INSERT TABLE 4]

\section{Discussion}

Policing activity shows similar overall trends in its concentration as crime activity, which can be expressed through the Gini coefficients of 0.89 and 0.92 for police presence and crime, respectively. However, at the micro level we have found a two-fold policing paradox. First, police presence and crime are misaligned in space and time. High concentrations of police presence are recorded at street segments that do not receive equally high proportions in crime, and vice versa. Temporally, police presence is recorded along a similar trajectory across hours of the day but appears to be ahead of crime by about three hours. Researchers have advocated constantly for hot spots orientated policing (e.g., Ariel et al., 2016; Ariel et al., 2019; Braga, Turchan et al., 2019; Braga, Weisburd, \& Turchan, 2019; Williams \& Coupe, 2017). In this regard, police activity must be focused on the right places and the right time. We see that there is an overall decline in the level of police deployed over the study period and over the course of the day. This might be due to staffing plans or administrative work that needs to be 
completed before the end of patrol shifts. As routine activities have been recognized as a cause of crime events (Cohen \& Felson, 1979), police (routine) activities could be more effective when orientated toward these ${ }^{13}$. This is not the case for our study. During summer, when arguably outdoor activities increasingly take place, the level of police was lowest. This could be caused by a lower number of patrol officers available during summer holidays. Further, crime risk is elevated when many people come together in time and space and thus creating more opportunities for crime (Felson \& Clarke, 1998; Nagin et al., 2015), which is visible in the analysed crime dataset. Arguably, times of high mobility (e.g., rush hours and commuting times) are moments when myriad crime opportunities arise. In our data we see that the policing activity responds to that general pattern during morning hours (6 a.m. to 10 a.m.) with a peak at around 9 a.m. The second peak of policing occurs around 2 p.m. and activity regresses towards the mean proportion afterwards. The pattern of police presence and crime could be better aligned by deploying police resources proportionally to recorded crime and potentially altering shifts in order to lower the three hours lag between police presence and crime.

Second, we found that an increase in the amount of police presence leads to higher concentration of presence at the street segments. In contrast, increases in the daily level of crime lead to lower crime concentrations. These antithetic relationships require considerations. We offer three. The sample size for the crime data is 52,512 , compared to 31,156 street segments. Theoretically, recorded crimes cannot be equally distributed across the street segments. Thus, around $31.5 \%$ of street segments $(n=9,800)$ would receive $50 \%$ less crime than the remaining street segments in a theoretical equal distribution. As we know from prior analysis (see, Weisburd 2015) and have demonstrated here, crime is highly concentrated and not randomly distributed on the micro level. Therefore, increasing numbers of crime raise the

\footnotetext{
${ }^{13}$ Felson questioned the ability of police officers to act as a guardian due to the unlikeliness of their presence as crimes occur infrequently and police beats are hard to cover in their entirety (Felson 2002)
} 
probability that we encounter less non-zero segments, as the number of street segments remains constant, and thus lower the concentration. In contrast, increases in police presence lead to an increase in its concentration. This, arguably, could be caused by their dependence to the street network. As we have seen in Figure 9, high concentrations of police presence are recorded isolated in the north and at longer street segments at the centre of the city. The high number of signals in the north is due proximity to the police station, where all patrol cars are parked. Longer street segments act as connectors in the street network and, as Davies and Bower (2019) remarked, show a high level of "betweenness". Police officers need to frequent these streets in order to reach their point of destination, may it be in response to an emergency call or during officer-initiated patrol. Therefore, these streets will inevitably show higher values of police presence. In contrast to crime, the entire trajectory of police vehicles is mapped and not just the event or patrol visits per se. Further, increases in the overall police presence and thus increases in the number of deployed patrol cars and teams, might free up officers to engage in self-initiated patrol. Therefore, high concentration of police presence at particular street segments might be a result of officer discretion in regard to patrolling activity and location.

That being said, the spatiotemporal concentration of police activity cannot be assessed on its singular structure alone. Methodological frameworks that focus on microlevels of space and time are needed to identify alignment between deployed police forces and reported crime. Police departments need to investigate where and when criminal activity occurs and based on that evidence shape their modus operandi of patrol and response. In our case we have found that police resources concentrate more when more time is spent in the field. Without knowledge on how this concentration is directed at places, an evaluation in terms of allocation remains impractical. In addition, theoretical and empirical implications need to be considered when looking at potential alignments and misalignments of police presence and crime. Prior research has shown that deterrent effects of police slowly decay over time, known as "deterrence decay" 
(see, Sorg et al., 2013). Following that, a certain temporal lead of police presence and a temporal (not spatial) misalignment might be favourable. When looking at the results of our analysis, we see that the overlap between police presence and crime is rather low $(\sim 23 \%)$ (see Table 5) over the course of the study period. This means that police focus seems to react little to spatial patterns of crime. This urges two future research paths. First, reliable measures need to be established to adequately assess the spatiotemporal focus of police on crime. By comparing policing programs in regard to their successfulness in deterring crime, the measures can be used to understand underlying spatiotemporal complexities and dependencies. Second, overall police presence needs to be investigated on a visit basis. Given that optimal crime deterrent effects are achieved by visits between 10 to 15 minutes (Koper, 1995), police presence needs to be assessed on this level. By doing so, we might be able to better understand how often police are at crime places and whether these everyday patrol visits are supporting crime deterrence.

In regard to comparability, we urge researchers and police departments alike to contribute to these novel findings of police concentration. As research has shown, focused police activity can deter crime effectively within high crime hot spots (e.g., Collazos et al., 2020). The adaption of this knowledge into policing practice can be evaluated by first investigating spatiotemporal concentrations of police presence and then by modelling hot spots and hot times of crime and police against each other. Yet, this framework is not to be seen as a measure to impose surveillance on police officers but to act as a retrospective feedback loop to improve and validate contemporary policing practices. In some cases, police departments might focus their policing activity to the most crime prone places but at the wrong times. In other cases, police officers might already be present in the right places and at the right time according to the local crime context and implementing innovative hot spots policing programs ends up being 
costly with no practical benefits. We now have the capabilities to inform police chiefs, officers, and researchers alike on the evidence of spatiotemporal concentration of police presence.

\section{Limitations}

The study needs to be viewed within its quantitative context and understood in regard to the analysed datasets. The developed map matching algorithm used static computation to assign each of the $77,680,983$ signals to the appropriate street segment. A static approach was necessary due to computational limitations. Even though the static map matching approach is exposed to inaccuracies of GPS signals and could potentially assign signals incorrectly to street segments, these inaccuracies are neglectable due to data size and precision. Our analysis focused on marked patrol cars of the APD $(n=130)$. These cars respond to emergency calls and take up patrol during the remainder of their shift. Thus, we cannot give any evidence in regard to policing activity of all police units (e.g., bike patrol, foot patrol, traffic patrol, unmarked service cars). However, our data are comprehensive for motor patrol units which make up most of policing resources (Ariel et al., 2019).

In this analysis police presence represents the time police patrol cars were recorded at different street segments. Due to the fact that the GPS data is retrieved from AVLs, there is no information regarding the number of officers present. Thus, we report police presence in patrol time and not officer time (see, Williams \& Coupe, 2017). GPS data do not show what officers are doing and why they police certain places more (or less) than others (Wain \& Ariel, 2014). This limitation can be overcome by developing and introducing novel spatiotemporal methodologies that combine data from, both, AVLs and officer worn radios. These methodologies might enable us to differentiate between times when officers are conducting motor patrol and when they are engaging in foot patrol. As the amount of recorded police data continuously grows, understanding qualitative aspects of police patrol and its management becomes equally important. 
Ultimately, a reflection on the interdependence of police and crime is appropriate. We used data about crime from an urban police department. It must be noted, that the Harbour districts in the North-West of the municipality belong to the Federal Police jurisdiction. Thus, crimes in these were not available for analysis. The provided data is limited to all recorded crime and can, naturally, not include criminal activity which was not reported to or by the police. Further, the identified misalignment of police presence and crime at the micro level could be caused by deterrent effects. Meaning that high levels of police presence at certain street segments might have deterred (potential) offenders from engaging in criminal activities in these particular places. Research designs that extend the temporal focus and add detailed analysis at the micro level of time and space will contribute to the understanding of how police forces are effectively deployed to prevent crime in everyday practice.

\section{Conclusions}

This analysis presents the first study that examined the concentration of police presence and crime and investigated both their spatial and temporal patterns. Police concentration and crime concentration follow similar patterns on the microlevel. By analysing over 77 million GPS signals from police patrol cars, we have shown that police concentration and crime concentration are misaligned, both, temporally and spatially. However, this temporal misalignment is partly caused by a lag of three hours and could be addressed through consolidation of officer shifts. This might indicate that police are already deterring crimes or that more patrol officers and units are needed to address crimes at later hours of the day. Further we found that police presence and crime are strongly concentrated within highest ranked street segments of police and crime. These preliminary results require more empirical backing through comparative analyses of both rural and urban environments to broaden evidence-based research on police presence. Nonetheless, our examination of police concentration implies the 
importance of research into the spatiotemporal dimensions of police work and the establishment of new data driven methodologies in police research.

\section{References}

Adler, N., Hakkert, A. S., Kornbluth, J., Raviv, T., \& Sher, M. (2014). Location-allocation models for traffic police patrol vehicles on an interurban network. Annals of Operations Research, 221(1), 9-31.

Andresen, M. A., Linning, S. J., \& Malleson, N. (2017). Crime at Places and Spatial Concentrations: Exploring the Spatial Stability of Property Crime in Vancouver BC, 2003-2013. Journal of Quantitative Criminology, 33(2), 255-275. https://doi.org/10.1007/s10940-016-9295-8

Andresen, M. A., Malleson, N., Steenbeek, W., Townsley, M., \& Vandeviver, C. (2020). Minimum geocoding match rates: an international study of the impact of data and areal unit sizes. International Journal of Geographical Information Science, 34(7), 1306-1322.

Ariel, B., Sherman, L. W., \& Newton, M. (2019). Testing hot-spots police patrols against notreatment controls: Temporal and spatial deterrence effects in the London Underground experiment. Criminology, 8(8), 1-27. https://doi.org/10.1111/1745-9125.12231

Ariel, B., Weinborn, C., \& Sherman, L. W. (2016). "Soft" policing at hot spots-do police community support officers work? A randomized controlled trial. Journal of Experimental Criminology, 12(3), 277-317.

Bernasco, W., \& Steenbeek, W. (2017). More Places than Crimes: Implications for Evaluating the Law of Crime Concentration at Place. Journal of Quantitative Criminology, 33(3), 451-467. https://doi.org/10.1007/s10940-016-9324-7 
Braga, A. A., Turchan, B. S., Papachristos, A. V., \& Hureau, D. M. (2019). Hot spots policing and crime reduction: an update of an ongoing systematic review and metaanalysis. Journal of Experimental Criminology, 15(3), 289-311.

Braga, A. A., Weisburd, D., \& Turchan, B. (2019). Focused deterrence strategies effects on crime: A systematic review. Campbell Systematic Reviews, 15(3).

Brantingham, P. L., \& Brantingham, P. J. (1993). Environment, routine and situation: Toward a pattern theory of crime. Advances in Criminological Theory, 5(2), 259-294.

Carrabine, E. (2009). Criminology: A sociological introduction (2. ed.). Routledge.

Chen, H., Cheng, T., \& Wise, S. (2015). Designing Daily Patrol Routes for Policing Based on Ant Colony Algorithm. ISPRS Annals of Photogrammetry, Remote Sensing and Spatial Information Sciences, II-4/W2, 103-109.

Cohen, L. E., \& Felson, M. (1979). Social-Change and Crime Rate Trends - Routine Activity Approach. American Sociological Review, 44(4), 588-608.

Collazos, D., García, E., Mejía, D., Ortega, D., \& Tobón, S. (2020). Hot spots policing in a high-crime environment: An experimental evaluation in Medellin. Journal of Experimental Criminology, 1-34.

Cordner, G. (1981). While on Routine Patrol: What the Police Do When They're Not Doing Anything. Am. J. Police, 1, 94.

Cordner, G. W. (1979). Police patrol work load studies: A review and critique. Police Stud.: Int'l Rev. Police Dev., 2, 50.

Cornish, D. B., \& Clarke, R. V. G. (Eds.). (1986). Research in criminology. The reasoning criminal: Rational choice perspectives on offending / edited by Derek B. Cornish, Ronald V. Clarke. Springer-Verlag. 
Davies, T., \& Bowers, K. (2019). Patterns in the supply and demand of urban policing at the street segment level. Policing and Society, 1-23.

DeAngelo, G., Toger, M., \& Weisburd, S. (2020). Police Response Times and Injury Outcomes. CEPR Discussion Papers.

Dewinter, M., Vandeviver, C., Vander Beken, T., \& Witlox, F. (2020). Analysing the Police Patrol Routing Problem: A Review. International Journal of Geo-Information, SUBMITTED (8).

Elevelt, A., Bernasco, W., Lugtig, P., Ruiter, S., \& Toepoel, V. (2019). Where You at? Using GPS Locations in an Electronic Time Use Diary Study to Derive Functional Locations. Social Science Computer Review, 13, 1-18.

Emsley, C. (1983). Policing and its Context 1750-1870. Macmillan Education UK. https://doi.org/10.1007/978-1-349-17043-2

Emsley, C. (Ed.). (2006). Police detectives in history, 1750 - 1950. Ashgate.

Famega, C. N. (2005). Variation in officer downtime: a review of the research. Policing: Int'l J. Police Strat. \& Mgmt., 28, 388.

Felson, M. (2002). Crime and everyday life. Sage.

Felson, M. (2008). Routine activity approach. In R. Wortley \& L. Mazerolle (Eds.), Environmental Criminology and Crime Analysis (70-77). Willan.

Felson, M., \& Clarke, R. V. (1998). Opportunity makes the thief. Police Research Series, Paper, 98, 1-36.

Felson, M., \& Poulsen, E. (2003). Simple indicators of crime by time of day. International Journal of Forecasting, 19(4), 595-601. 
Hutt, O., Bowers, K., Johnson, S., \& Davies, T. (2018). Data and evidence challenges facing place-based policing. Policing: An International Journal of Police Strategies \& Management.

Hutt, O. K. (2020). Understanding the deterrent effect of police patrol [, UCL (University College London)]. EndNote Tagged Import Format.

Kelling, G. L., Pate, T., Dieckman, D., \& Brown, C. E. (1974). The Kansas City Preventive Patrol Experiment: A Summary Report. Washington. Police Foundation.

Kenneth R. Chelst (1981). Deployment of One- vs. Two-Officer Patrol Units: A Comparison of Travel Times. Management Science, 27(2), 213-230.

Koper, C. S. (1995). Just enough police presence: Reducing crime and disorderly behavior by optimizing patrol time in crime hot spots. Justice Quarterly, 12(4), 649-672.

Koper, C. S., Lum, C., Wu, X., \& Fritz, N. (2020). Proactive policing in the United States: a national survey. Policing: An International Journal of Police Strategies \& Management.

Levin, A., Rosenfeld, R., \& Deckard, M. (2017). The law of crime concentration: An application and recommendations for future research. Journal of Quantitative Criminology, 33(3), 635-647.

Li, L., Jiang, Z., Duan, N., Dong, W., Hu, K., \& Sun, W. (2011, January). Police Patrol service optimization based on the spatial pattern of hotspots. In 2011 IEEE International Conference on Service Operations, Logistics, and Informatics (pp. 45-50). IEEE. https://doi.org/10.1109/SOLI.2011.5986526

Lum, C. M., \& Koper, C. S. (2017). Evidence-based policing: Translating research into practice. Oxford University Press Oxford, UK.

McCabe, J. (2013). An analysis of police department staffing: How many officers do you really need. ICMA Center for Public Safety Management White Paper. 
Mitchell, R. J. (2017). Frequency versus duration of police patrol visits for reducing crime in hot spots: non-experimental findings from the Sacramento hot spots experiment. Cambridge Journal of Evidence-Based Policing, 1(1), 22-37.

Nagin, D. S., Solow, R. M., \& Lum, C. (2015). Deterrence, criminal opportunities, and police. Criminology, 53(1), 74-100.

Oatley, G., Barnes, G. C., Clare, J., \& Chapman, B. (2019). Crime concentration in Perth CBD: a comparison of officer predicted hot spots, data derived hot spots and officer GPS patrol data. Australian Journal of Forensic Sciences, 51(1), 136-140.

Ratcliffe, J. H. (2010). Crime Mapping: Spatial and Temporal Challenges. In A. R. Piquero \& D. Weisburd (Eds.), Handbook of quantitative criminology (5-24). Springer.

Ridgeway, G. (2018). Policing in the era of big data.

Sacks, S. R. (2000). Optimal spatial deployment of police patrol cars. Social Science Computer Review, 18(1), 40-55.

Schaefer, B. P., Hughes, T., \& Cameron Stelzig, W. (2019). Hot spots across the metropolis: Evaluating hot spots directed patrol at city and suburban locations. Justice Quarterly, 123.

Sherman, L. W. (Ed.). (2006). Evidence-based crime prevention (Rev. ed.). Routledge.

Sherman, L. W. (2013). The Rise of Evidence-Based Policing: Targeting, Testing, and Tracking. Crime and Justice, Vol 43: Why Crime Rates Fall, and Why They Don't, 42(1), $377-451$.

Sorg, E. T., Haberman, C. P., Ratcliffe, J. H., \& Groff, E. R. (2013). Foot Patrol in Violent Crime Hot Spots: The Longitudinal Impact of Deterrence and Posttreatment Effects of Displacement. Criminology, 51(1), 65-101. https://doi.org/10.1111/j.17459125.2012.00290.x 
Telep, C. W. (2013). Moving Forward with Evidence-Based Policing: What Should Police Be Doing and Can We Get Them to Do It? George Mason University.

Vandeviver, C., \& Bernasco, W. (2017). The geography of crime and crime control. Applied Geography, 86, 220-225.

Vandeviver, C., \& Steenbeek, W. (2019). The (in) stability of residential burglary patterns on street segments: the case of Antwerp, Belgium 2005-2016. Journal of Quantitative Criminology, 35(1), 111-133.

Wain, N., \& Ariel, B. (2014). Tracking of police patrol. Policing: A Journal of Policy and Practice, 8(3), 274-283.

Weisburd, D. (2015). The Law of Crime Concentration and the Criminology of Place. Criminology, 53(2), 133-157.

Weisburd, D., Telep, C. W., Braga, A. A., \& Groff, E. R. (2010). The importance of place in policing: Empirical evidence and policy recommendations. Brottsförebyggande rådet (BRA) Stockholm.

Williams, S., \& Coupe, T. (2017). Frequency vs. length of hot spots patrols: a randomised controlled trial. Cambridge Journal of Evidence-Based Policing, 1(1), 5-21. 


\section{Figures \& Tables}
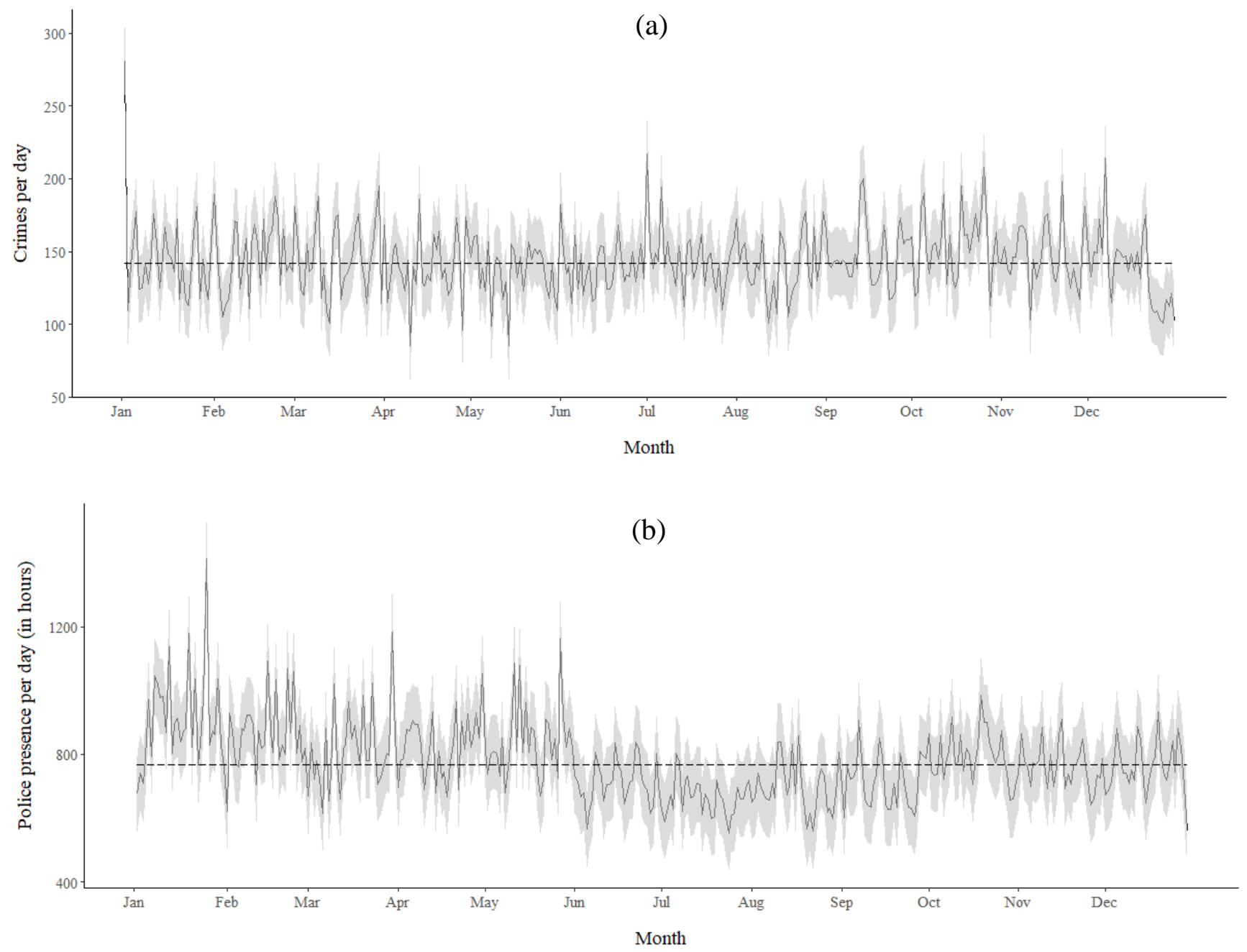

Figure 1: Daily levels of crime (a) and police presence (b) in 2019. Dotted line indicates annual median. 

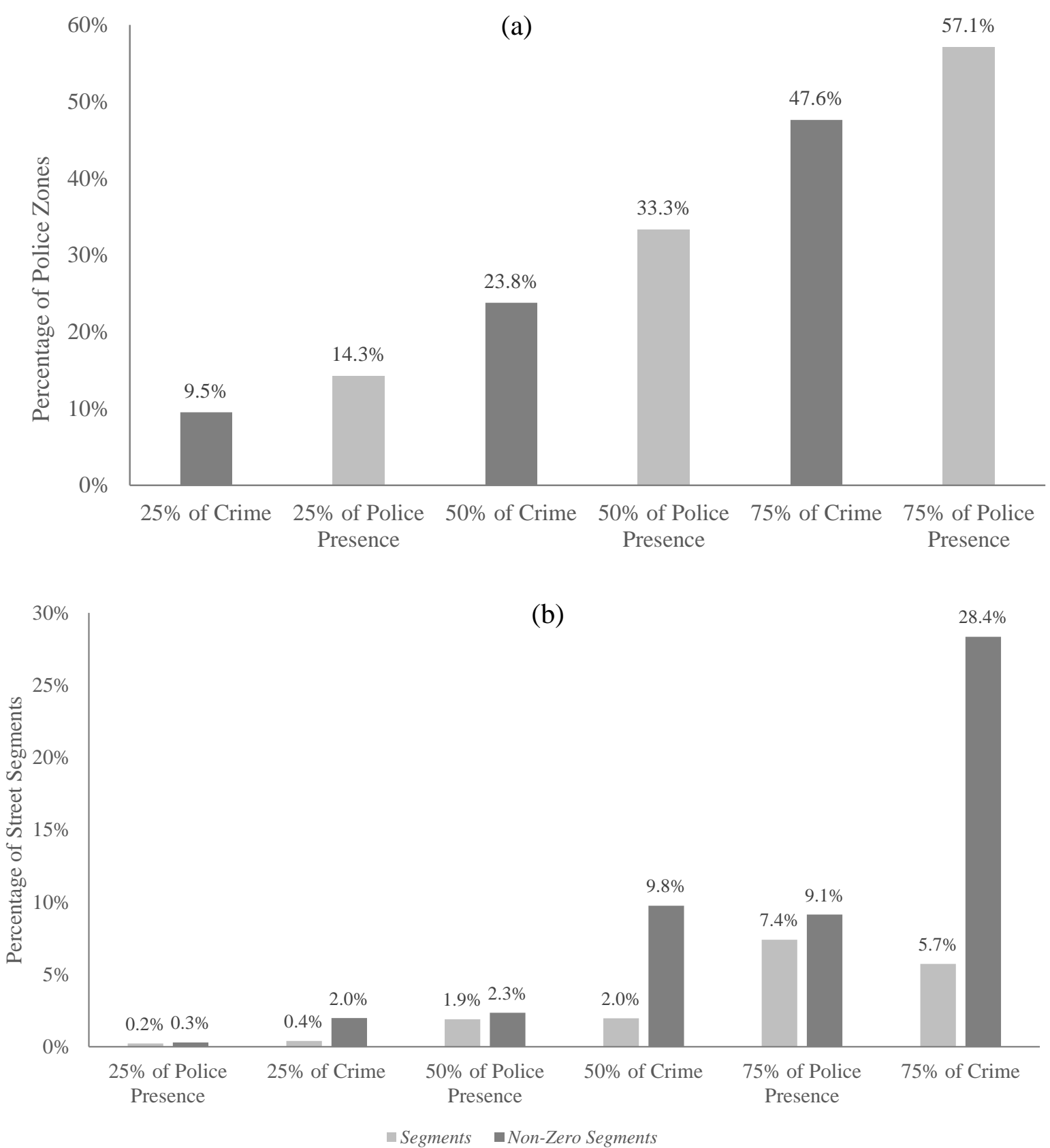

Figure 2: Concentration of crime and police across police zones $(a)(n=21)$ and street segments $(b)(n=31,156)$. 
(S) Table 1: Overview of concentration of police presence and crime in proportions across all units of analysis.

\begin{tabular}{lccc}
\hline & Police Zones & Street Segments & Non-Zero Segments \\
\hline $25 \%$ of Police Presence & 0.143 & 0.002 & 0.003 \\
$50 \%$ of Police Presence & 0.333 & 0.019 & 0.023 \\
$75 \%$ of Police Presence & 0.571 & 0.074 & 0.091 \\
At least 1 visit & 1 & 0.814 & 1 \\
& & & \\
Min & 0.019 & 0 & 0.000 \\
Max & 0.085 & 0.015 & 0.015 \\
Mean & 0.048 & 0.000 & 0.000 \\
SD & 0.018 & 0.000 & 0.000 \\
$\mathrm{~N}$ & 21 & 31,156 & 25,373 \\
\hline
\end{tabular}

\begin{tabular}{lccc}
\hline & Police Zones & Street Segments & Non-Zero Segments \\
\hline $25 \%$ of Crime & 0.095 & 0.004 & 0.020 \\
$50 \%$ of Crime & 0.286 & 0.020 & 0.098 \\
$75 \%$ of Crime & 0.524 & 0.057 & 0.284 \\
At least 1 crime & 1 & 0.202 & 1 \\
& & & \\
Min & 0.005 & 0 & 0.000 \\
Max & 0.135 & 0.012 & 0.012 \\
Mean & 0.048 & 0.000 & 0.000 \\
SD & 0.031 & 0.000 & 0.000 \\
$\mathrm{~N}$ & 21 & 31,156 & 6,296 \\
\hline
\end{tabular}




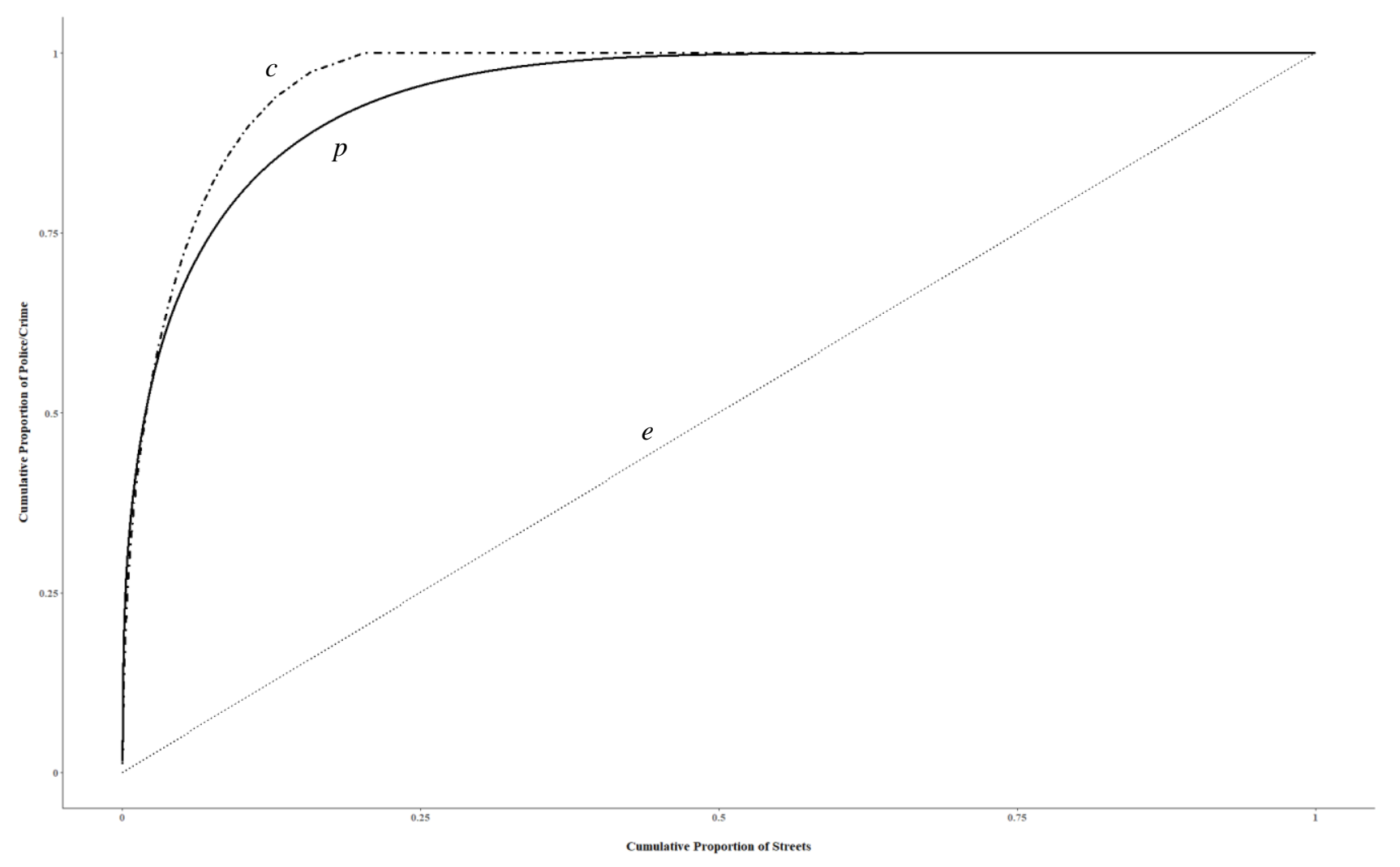

Figure 3: Lorenz curve for distribution of police presence (p) and crime (c) across street segments. $e$ represents a theoretical equal distribution.

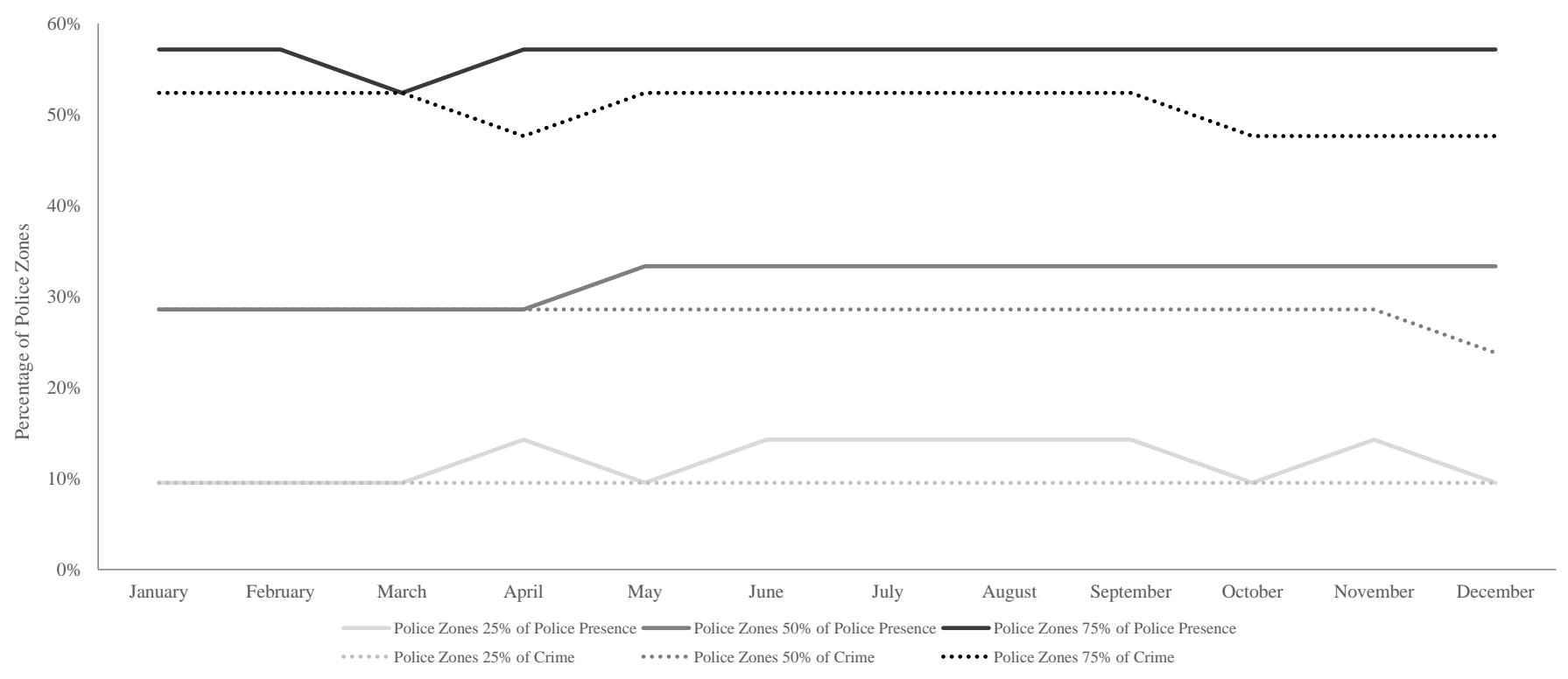

(S) Figure 4: Concentration of police presence and crime across police zones. 


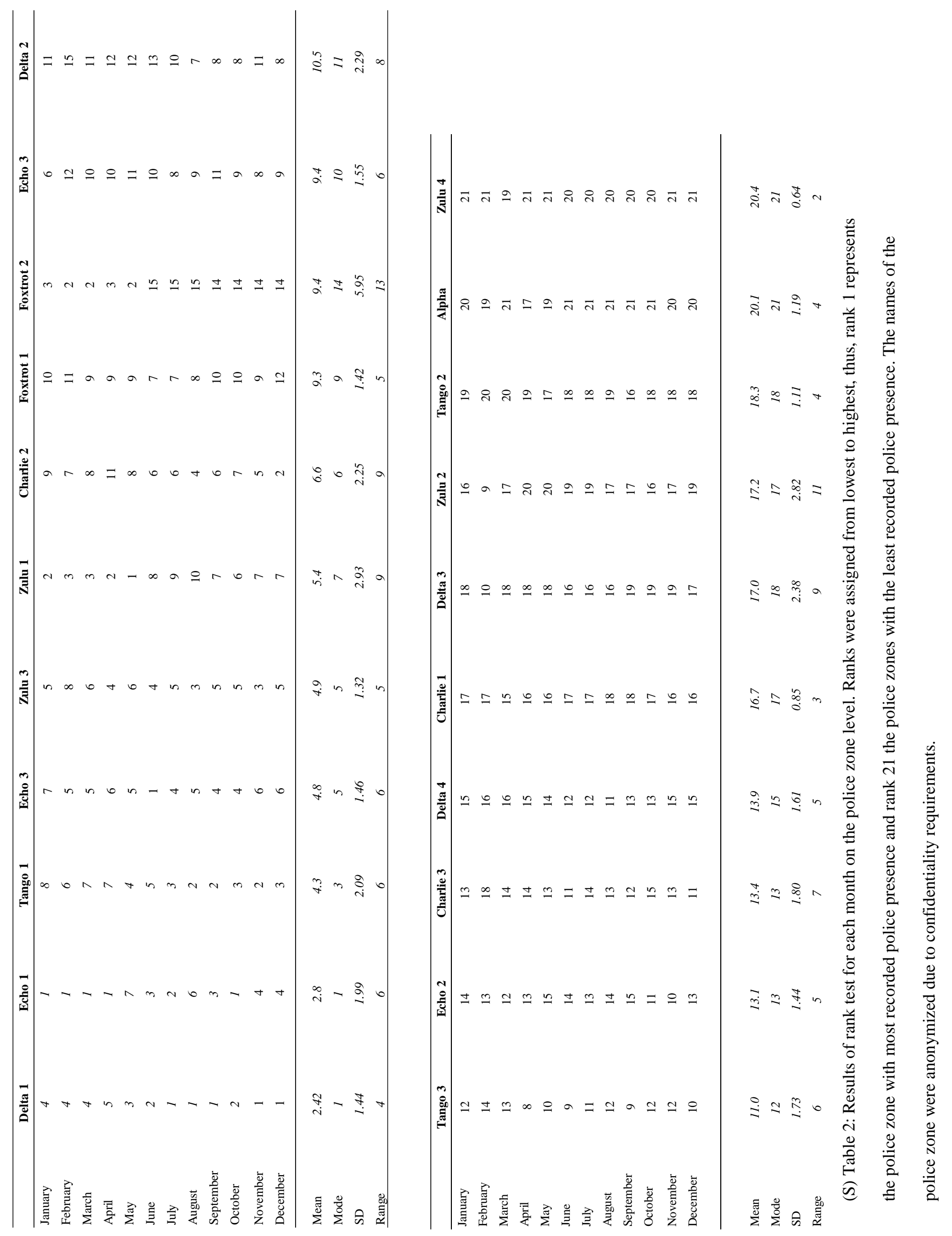


(a)

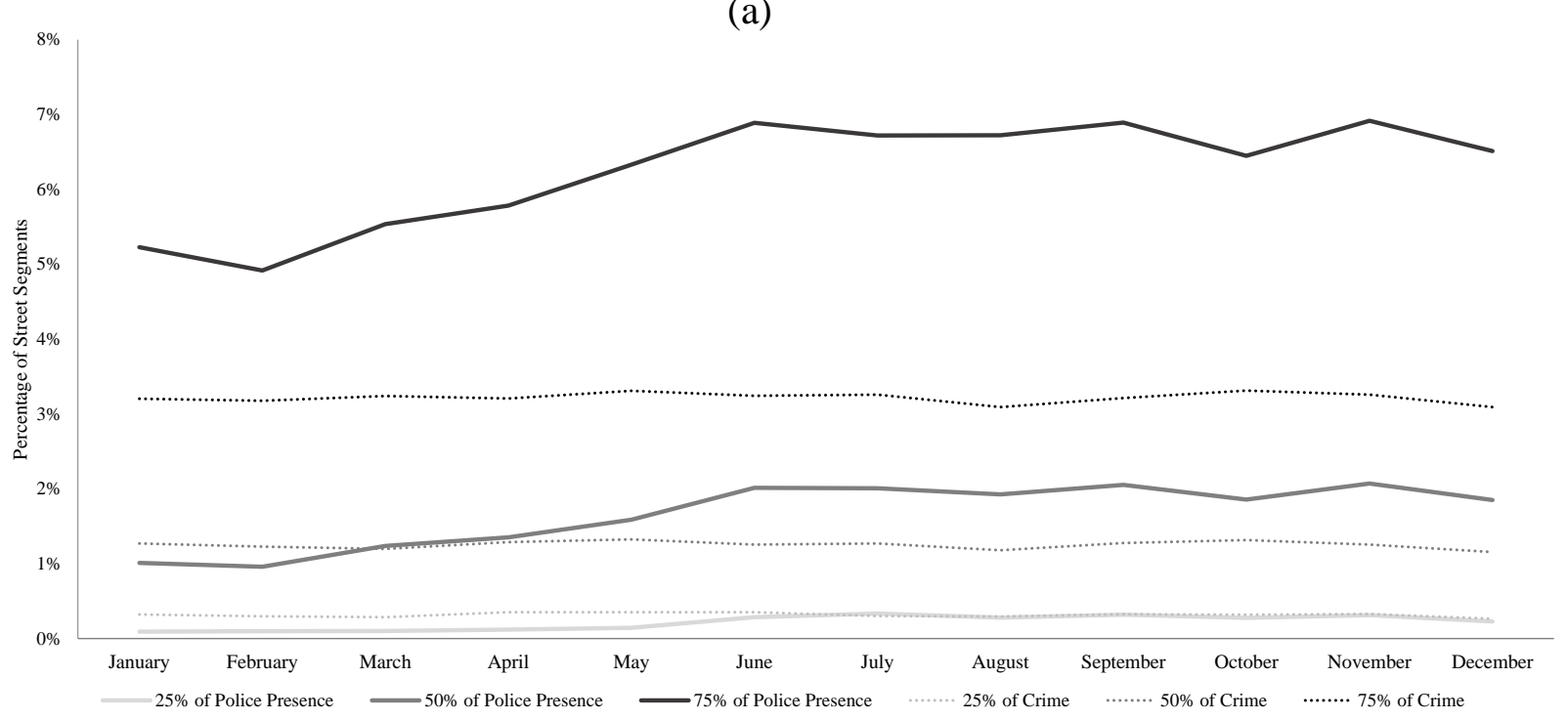

(b)

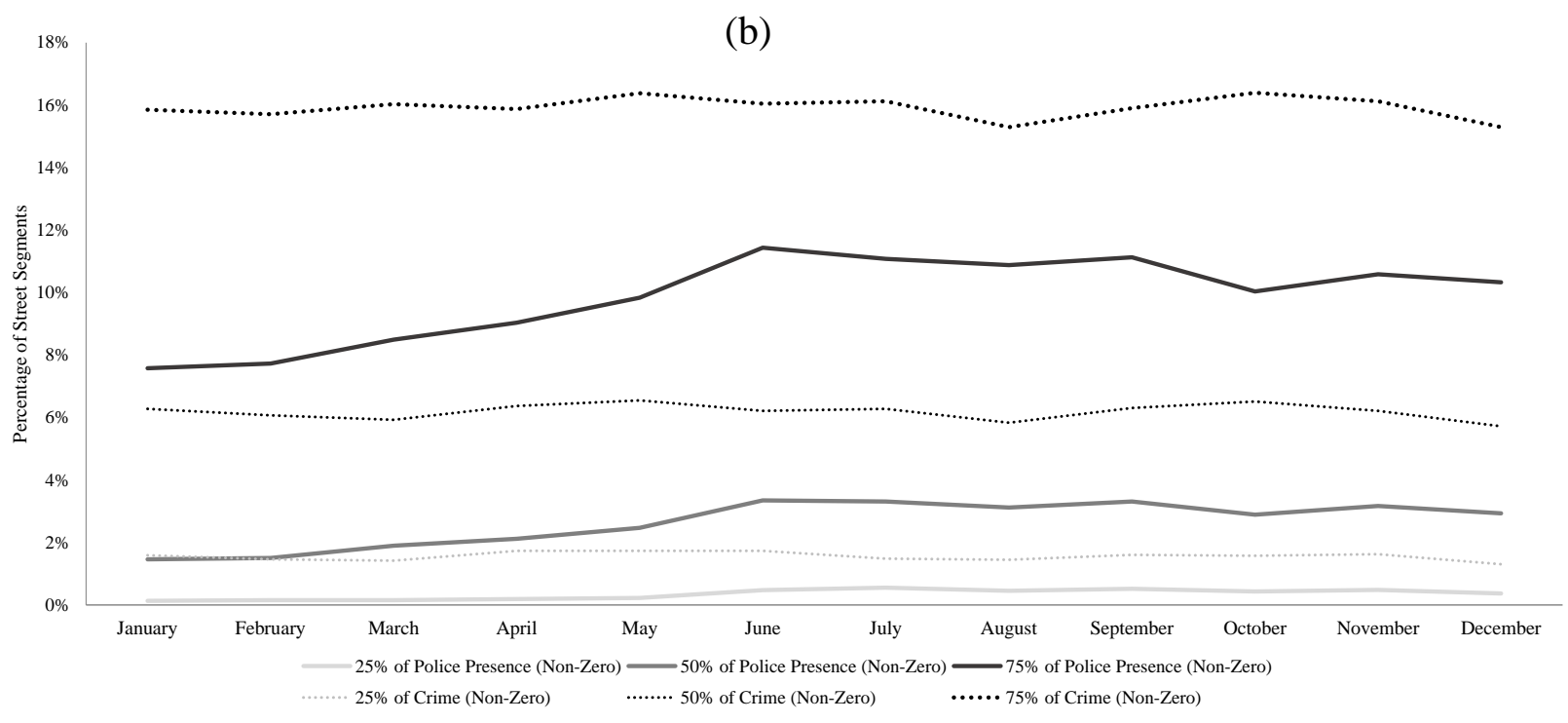

(S) Figure 5: Concentration of police presence and crime across street segments (a) and non-zero street segments (b). 


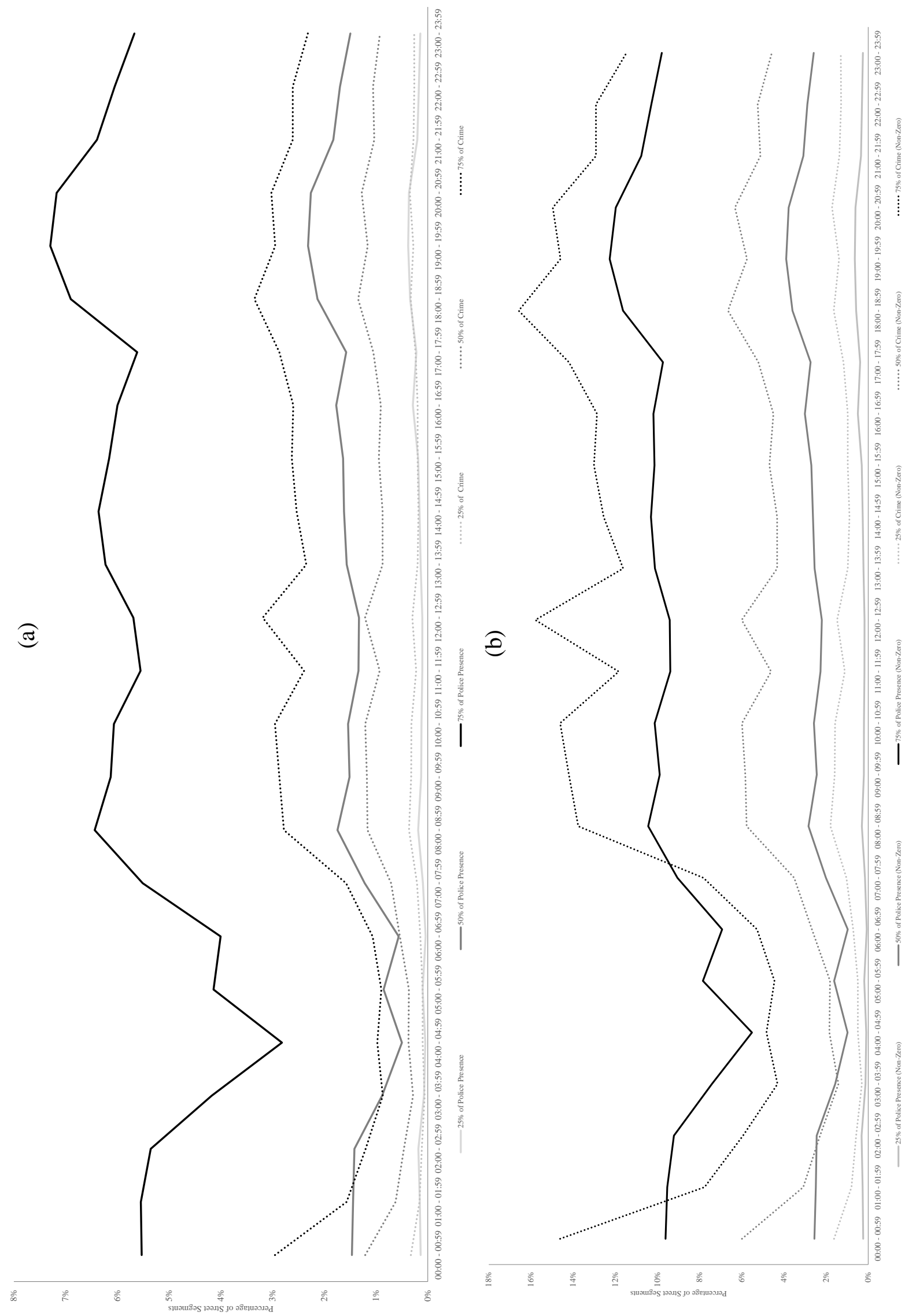

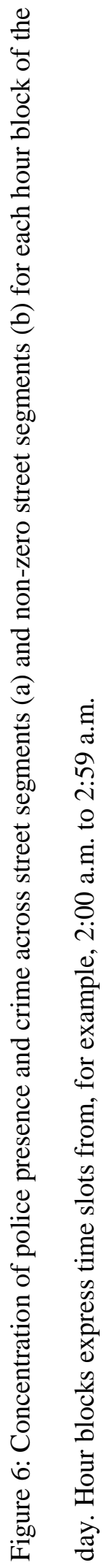




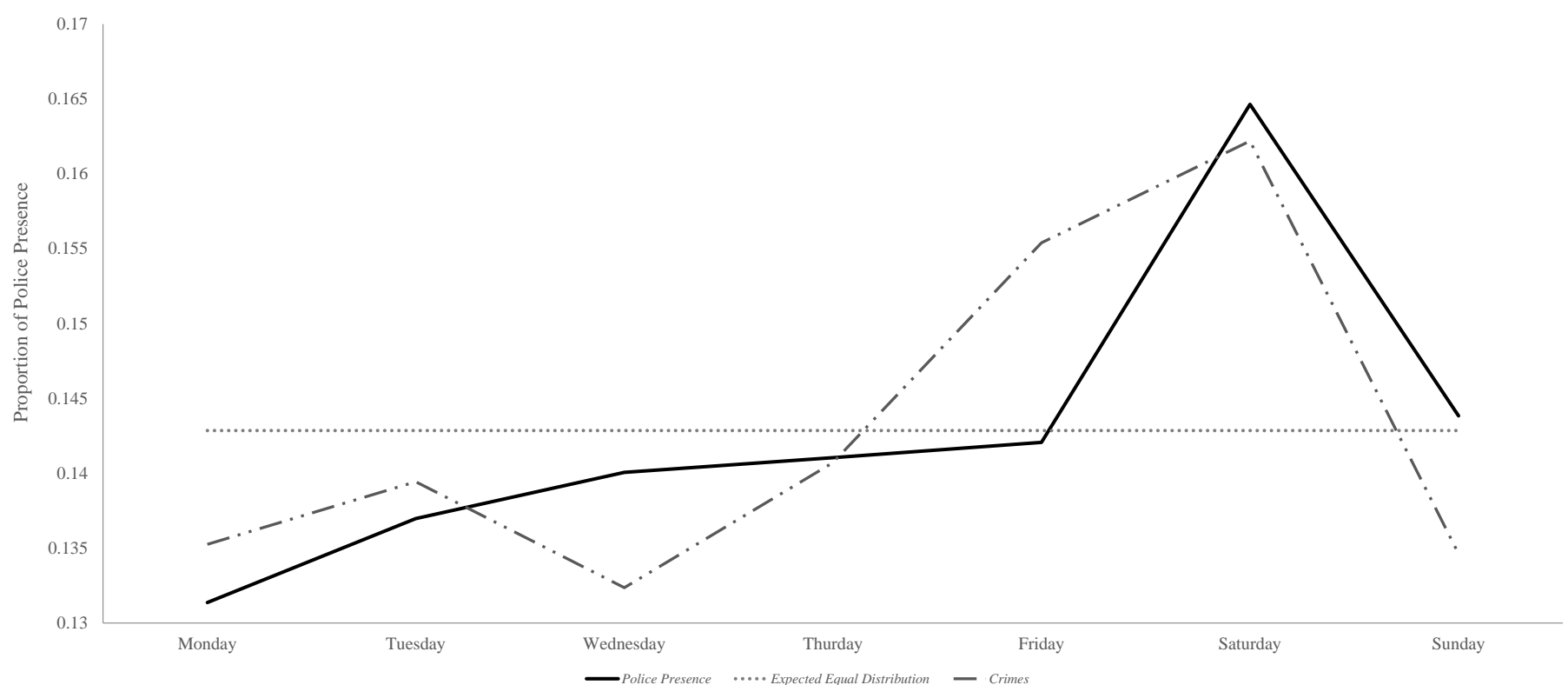

Figure 7: Proportions of police presence and crime for each day of the week. Dotted line expresses theoretical equal proportions.

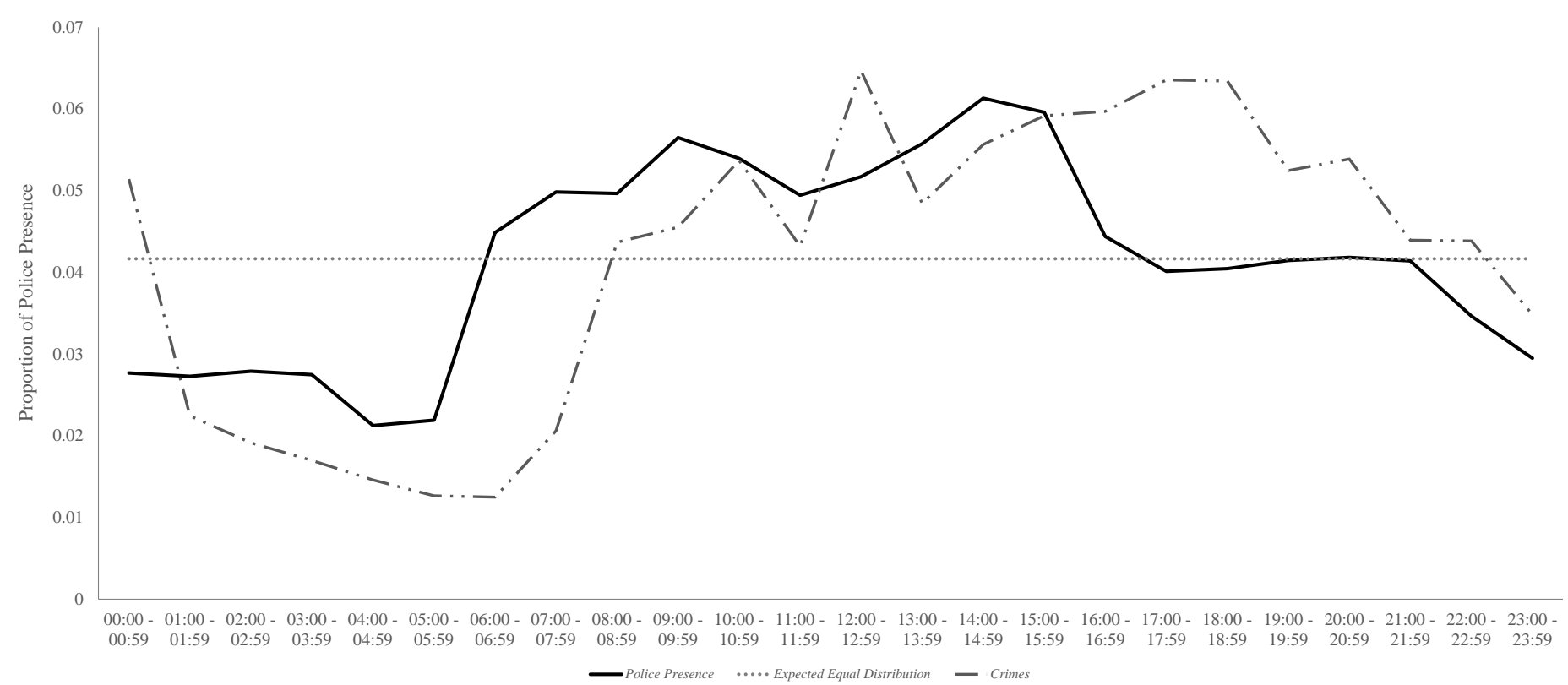

Figure 8: Proportions of police presence and crime for each hour block of the day. Dotted line expresses theoretical equal distribution. 


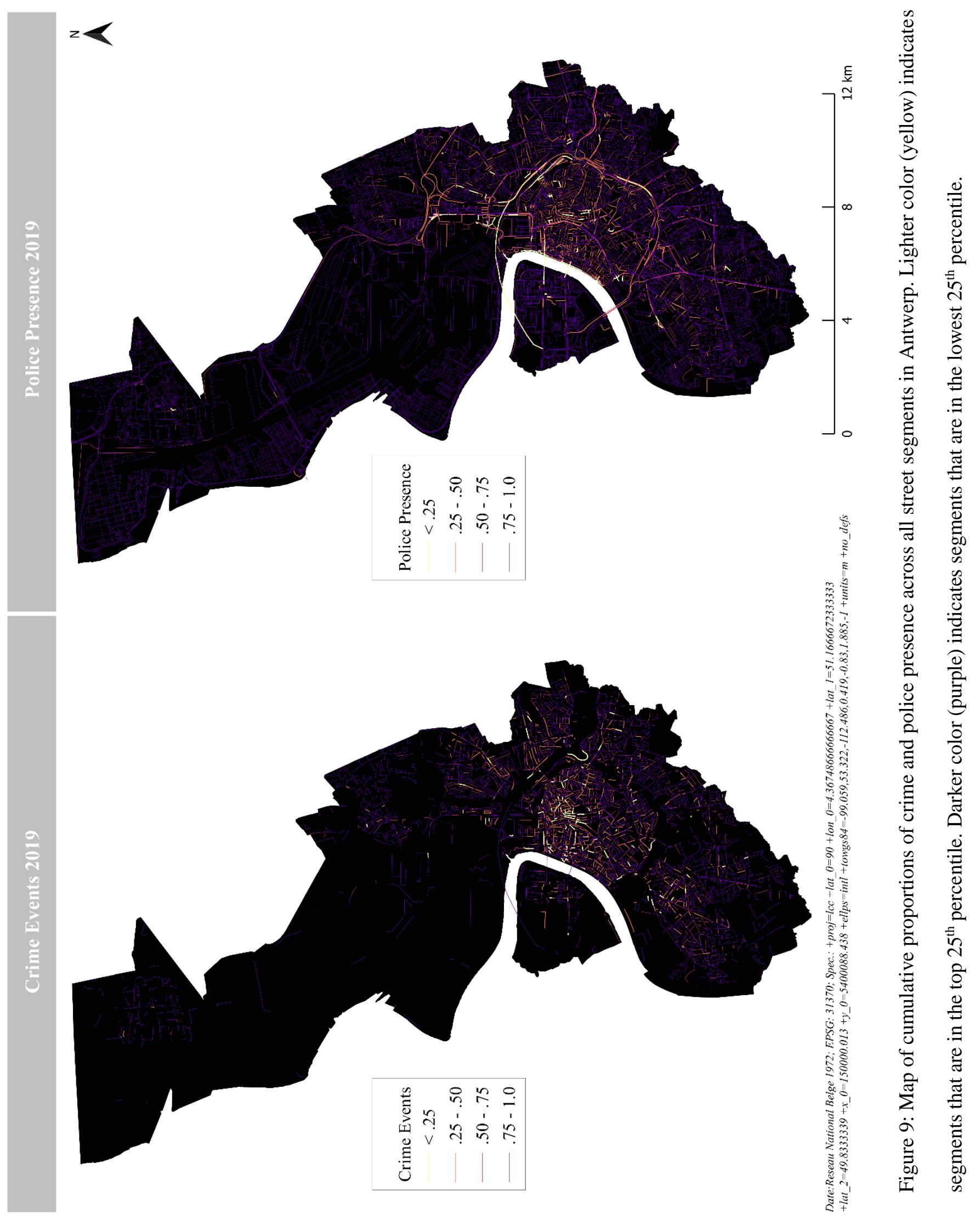




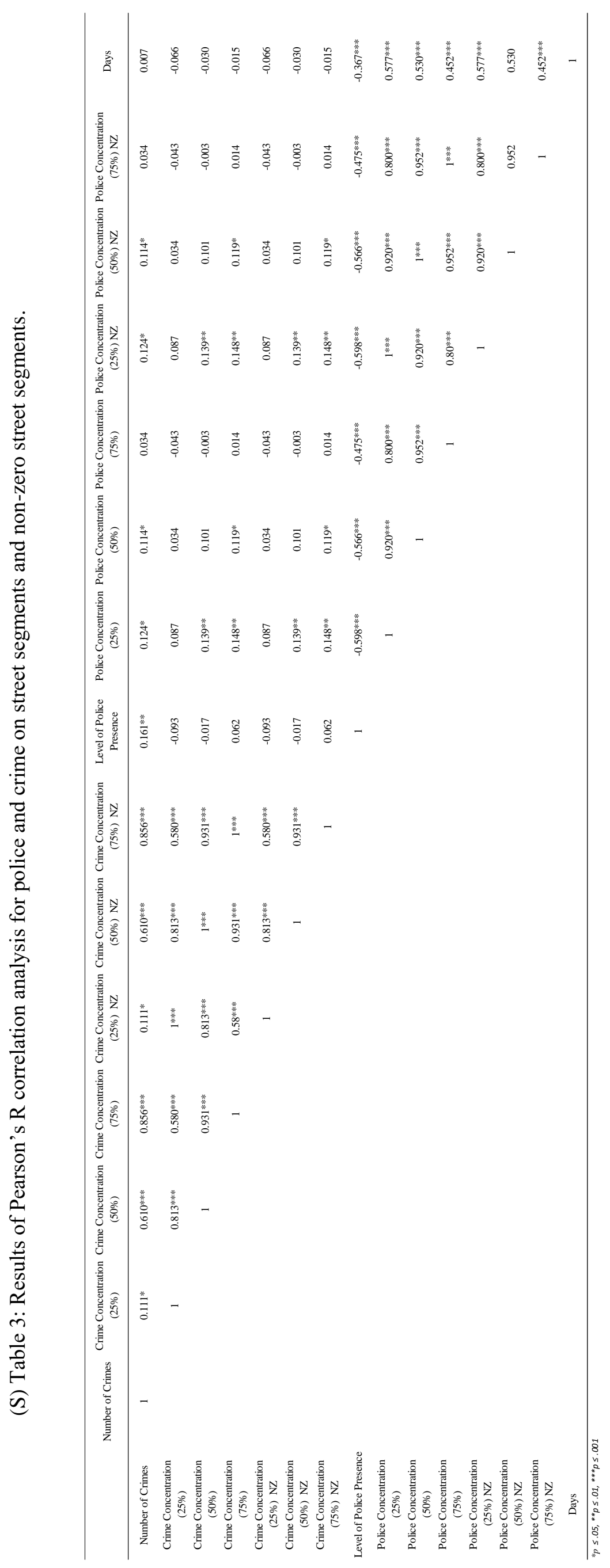




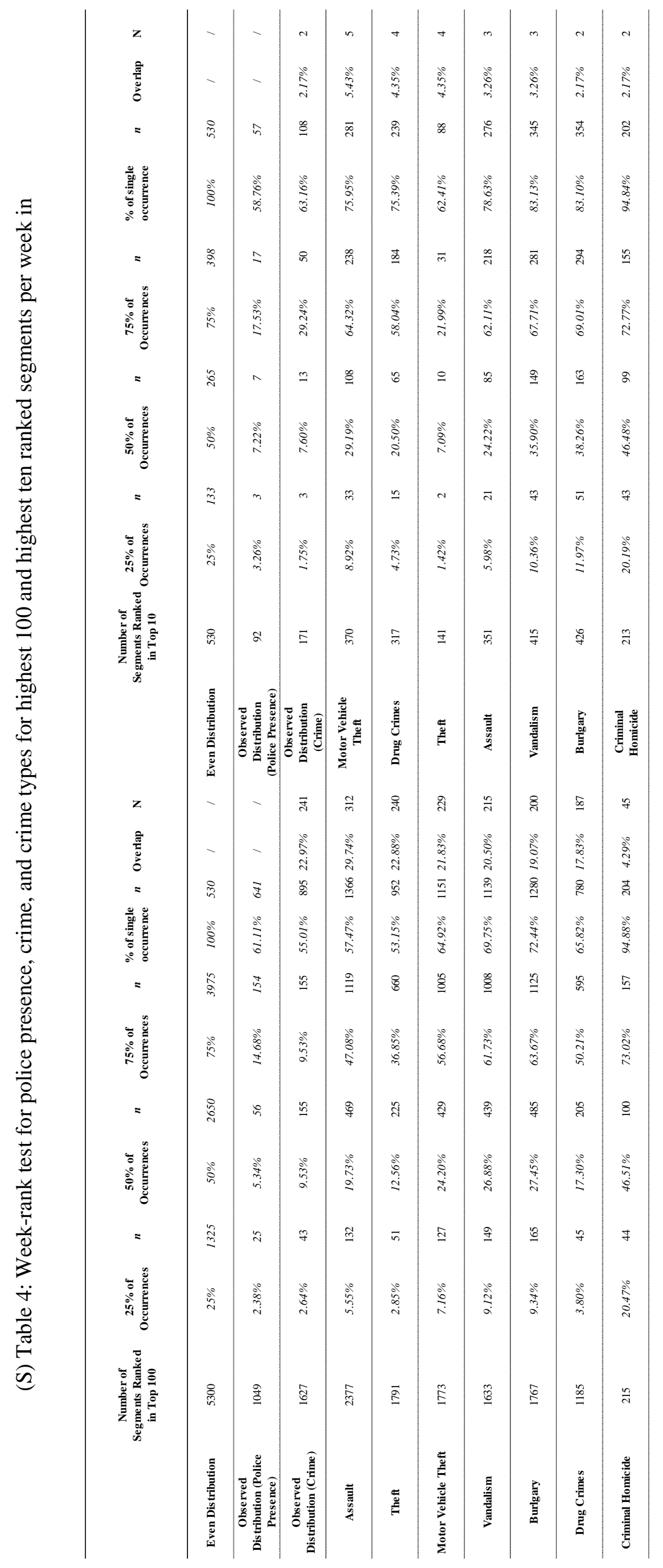

